\title{
Going beyond the situational judgment test: the true impact of the educational performance measure, publications, and extra-degree performance on the foundation program application
}

\author{
Meelad Sayma ${ }^{1,2}$ \\ Shiraz Jamshaid' \\ Doa'a Kerwat ${ }^{1,3}$ \\ Dina Saleh' \\ Aaniya Ahmed' \\ Folashade Oyewole' \\ Abdul Samad Wahid \\ ' Imperial College Business School, \\ Imperial College London, London, \\ ${ }^{2}$ Peninsula College of Medicine and \\ Dentistry, Plymouth, Devon, ${ }^{3}$ Barts \\ and The London School of Medicine \\ and Dentistry, London, UK
}

This article was published in the following Dove Press journal:

Advances in Medical Education and Practice

9 February 2016

Number of times this article has been viewed

\section{Dear editor}

We read with great interest the expert opinion of Singagireson et al and agree with the key points raised. ${ }^{1}$ However, this can be seen to be only one part of the multidimensional foundation program application. It is important to add that we feel there are multiple inequitable components that impact on UK medical students' foundation program application.

The author emphasizes that the situational judgment test (SJT) and medical school performance make up two points of the application performance; however, there are two factors that have a larger-than appreciated impact on the foundation program application - "PubMed-referenced publications" and additional degrees (eg, an intercalated BSc or PhD). ${ }^{2}$

The author raises the question of significant disparities between the opportunities available at medical schools across the UK. This is clearly shown in the national variability in intercalation opportunities - some medical schools offer compulsory BScintercalated programs, whereas some schools offer only intercalated degrees to up to a maximum of one-fifth of their students. ${ }^{3,4}$ Similarly, the foundation program accepts applications from postgraduate medical students who may have previous masters or even $\mathrm{PhDs}$. There are up to five points available for an extra degree in the foundation program application, out of 100; the presence of a $\mathrm{PhD}$ adds five application points, with a Master's or Bachelor's degree contributing up to four points. ${ }^{2}$

In addition, publications are valued at up to two points in the foundation program application where one point is available for each PubMed-referenced publication a student has authored, up to a maximum of two points. ${ }^{2}$ It can be argued that the skills learnt from extra degrees give medical students a far greater opportunity to do research and publish work in a particular field. ${ }^{5}$ Thus, individuals who have been given an opportunity to study for an extra degree are at an advantage in more than one way when approaching their foundation program application.

\section{Why is this relevant?}

In total, up to seven additional points are available outside of medical school and SJT performance. Seven points seem minimal in the context of the application; however, 
we would like to place great emphasis on the fact that points gained for actual medical school performance (Education Performance Measure [up to 43 points for medical school performance, up to 5 points for extra degrees, and up to 2 points for publications (one per PubMed referenced publication)]) range from a minimum of 34 (worst-performing students) to a maximum of 43 points (best-performing students). ${ }^{2}$ As a result, a student with a poor Education Performance Measure score, but with an additional degree and publications, would effectively be ranked similarly to a high-performing individual who has not had the opportunities to undertake an extra degree. While it may be argued that these extra points are well deserved as these degrees and publications can take years to conduct, not all students are given the same opportunities to obtain these qualifications. As a result, we find the current system inequitable in more than one way.

In reference to the expert opinion regarding SJT by Singagireson et al, we agree that the SJT has a disproportionately large impact on students. ${ }^{1}$ The purpose of this response is to add to the fact that opportunities to undertake an additional degree or obtain publications are arguably more impactful on the application than the SJT. The SJT may be weighted as 50\% of the application; however, in 2015 the standard deviation for all medical school SJT scores equated to 4.02 points. ${ }^{6}$ Similarly, the standard deviation of the overall application points across all medical schools was 6.10 points. $^{6}$ These statistics indicate the narrow range in which all medical students lie when undertaking the SJT and the application as a whole. Simultaneously, these figures illustrate the importance of an additional degree and/ or publications to the foundation program application, with a small addition in points giving an individual a significant boost in terms of ranking position.

\section{Conclusion}

To conclude, the gap between medical students in the UK from different medical schools is narrow, in terms of educational performance and overall application scoring. Small differences in terms of publications and degree performance make what could be perceived as a disproportionately large difference to the foundation program application score, especially when considering their potential inequitability. As a result, these contributors to the foundation program application system should also be considered along with the SJT when debating how we can most fairly allocate jobs to our most junior of doctors in the UK.

\section{Disclosure}

The authors report no conflicts of interest in this communication.

\section{References}

1. Singagireson S, Ramjeeawon N, Ravindra S, Shah N, Singh B. Is it fair for a junior doctor's deanery to be largely based on one test: a student's perspective. Adv Med Educ Pract. 2015;6:499-500.

2. FP/AFP 2016: Applicants Handbook; June 2015. The UK Foundation Programme Office [cited November 19, 2015]. Available from: http:// www.foundationprogramme.nhs.uk/pages/academic-programmes/howto-apply. Accessed November 19, 2015.

3. Undergraduate: Medicine (MBBS/BSc); 2015 [cited November 19, 2015]. Imperial College London. Available from: https://www.imperial.ac.uk/study/ug/courses/school-of-medicine/medicine/. Accessed November 19, 2015.

4. Undergraduate study: BMBS Medicine; 2015; [cited November 19, 2015]. University of Exeter; 2015. Available from: http://www.exeter. ac.uk/undergraduate/degrees/medicine/medicine/\#Intercalation. Accessed November 19, 2015.

5. Metcalfe D. Involving medical students in research. $J R$ Soc Med. 2008;101(3):102-103.

6. Foundation Programme 2015 Recruitment Stats and Facts Interim report; 20 April 2015. The UK Foundation Programme Office. Available from: http://www.foundationprogramme.nhs.uk/pages/home/keydocs . Accessed January 28, 2016.

Dove Medical Press encourages responsible, free and frank academic debate. The content of the Advances in Medical Education and Practice 'letters to the editor' section does not necessarily represent the views of Dove Medical Press, its officers, agents, employees, related entities or the Advances in Medical Education and Practice editors. While all reasonable steps have been taken to confirm the content of each letter, Dove Medical Press accepts no liability in respect of the content of any letter, nor is it responsible for the content and accuracy of any letter to the editor.

\section{Publish your work in this journal}

Advances in Medical Education and Practice is an international, peerreviewed, open access journal that aims to present and publish research on Medical Education covering medical, dental, nursing and allied health care professional education. The journal covers undergraduate education, postgraduate training and continuing medical education including emerging trends and innovative models linking education, research, and health care services. The manuscript management system is completely online and includes a very quick and fair peer-review system. Visit http://www.dovepress.com/testimonials.php to read real quotes from published authors.

Submit your manuscript here: http://www.dovepress.com/advances-in-medical-education-and-practice-journal 